\title{
3 Research Square

\section{Impact of Urban Family Physician Program on health indicators in Iran: an Interrupted Time Series Analysis}

\section{Parisa Hajibadali}

Tabriz University of Medical Sciences

Minasadat Hashemiparast

Maragheh University of Medical Sciences

Zeinab Iraji

Tabriz University of Medical Sciences

Elham Lotfalinejad

Tabriz University of Medical Sciences

\section{Hamid Allahverdipour}

Tabriz University of Medical Sciences

Haidar Nadrian ( $\square$ haidarnadrian@gmail.com )

Tabriz University of Medical Sciences https://orcid.org/0000-0003-3129-2475

\section{Research article}

Keywords: Family Physician Program, Urban areas, Health indicators, Outcome

Posted Date: July 16th, 2020

DOI: https://doi.org/10.21203/rs.3.rs-42089/v1

License: (c) (1) This work is licensed under a Creative Commons Attribution 4.0 International License. Read Full License 


\section{Abstract}

\section{Background}

In 2015, the Iranian Urban Family Physician Program (UFPP) was implemented in urban health centers. In the present study, we aimed to evaluate the trend of health indicators across a ten-year period in an Iranian population and to measure the possible effects of this intervention on health indicators.

\section{Methods}

An interrupted time series analysis (ITSA) was performed on a ten-years (from 2009 to 2018) of annual data set covering all healthcare indicators associated to the UFPP in Bonab County, Iran. The time of intervention was at the 7th data point in 2015. Health indicators were divided into two groups including process indicators (Modern Contraceptives Use (MCU), Prenatal and Postpartum care visits, Clinical Breast Examinations (CBE), brucellosis and tuberculosis (TB) incidence), and outcome indicators (Total fertility rate (TFR), Maternal Mortality Rate (MMR), Stillbirth Rate (SBR), Infant mortality Rate (IMR), Neonatal Mortality Rate (NMR), 1-59 months old Mortality Rate, Low Birth Weight (LBW), crud birth rate (CBR) and the rates of Infants fed by Formula milk.

Results

The ratio of some process indicators, including the $\mathrm{MCU}(\mathrm{b}=-5.13 .95 \%$ Confidence Interval $(\mathrm{Cl}):-8.01$ to -2.26), incidence of tuberculosis ( $b=.016 .95 \% \mathrm{Cl}:-1.01$ to 1.34 ) and brucellosis ( $b=3.04 .95 \% \mathrm{Cl}:-3.4$ to 9.50) had a decreasing trend from 2008 to 2018 . However, the CBE ( $b=0.60 .95 \% \mathrm{Cl}:-4.97$ to 6.18$)$, prenatal care visits, $(b=-4.25 .95 \% \mathrm{Cl}:-10.4$ to 1.5$)$ postpartum care visits ( $b=-22.83$. $95 \% \mathrm{Cl}:-31.44$ to $-14.21)$, and first time care visits during pregnancy ( $b=-5.59 .95 \% \mathrm{Cl}:-14.52$ to 3.32$)$ were found with increasing trends. In contrast, the rate of at least six-time care visits during pregnancy was found to be in a decreasing trend $(b=-10.32 .95 \% \mathrm{Cl}:-16.82$ to -3.82$)$. A series of outcome indicators including MMR ( $b$ $=24.78 .95 \% \mathrm{Cl}: 2.88$ to 46.61$),$ TFR $(b=0.07 .95 \% \mathrm{Cl}: 0.01$ to 0.13$), 1-59$ Month old Mortality Rate $(b=$ - .16. $95 \% \mathrm{Cl}:-.45$ to .12$)$, LBW ( $b=.33 .95 \% \mathrm{Cl}:-.08$ to .40$)$, Formula-fed infant rate $(\mathrm{b}=.48 .95 \% \mathrm{Cl}$ : -.007 to .97$)$, Delivery rate in high-risk groups ( $b=1.85 .95 \% \mathrm{Cl}: 1.22$ to 2.49$)$ and CS ( $b=-3.43 .95 \% \mathrm{Cl}$ : -5.73 to -1.12$)$ had increasing trends from 2008 to 2018 . In contrast, SBR $(b=-.04 .95 \% \mathrm{Cl}:-.21$ to .12$)$, NMR ( $b=-.77 .95 \% \mathrm{Cl}:-2.91$ to 1.36$)$, IMR $(b=-1.05 .95 \% \mathrm{Cl}:-2.99$ to .89$)$ and CBR ( $b=-.97 .95 \% \mathrm{Cl}$ : -1.85 to -.09$)$ were in decreasing trends.

\section{Conclusion}

The UFPP was found with positive impacts on some process, proximal and distal outcome indicators, but its positive impacts on the trends of some critical indicators, including MMR, NMR and IMR remained questionable. Our findings may shed light on the role of some other factors like social determinants of health in the programs like the UFPP. 


\section{Introuduction}

In each society, it is critical to provide health care services in various physical, mental, social and spiritual dimensions [1]. In this regard, the World Health Organization (WHO) has determined three crucial objectives to establish outstanding health system: Health care provision using reliable standards, optimal accountability and health equity-based provision of health services among families [2]. Despite efforts in various countries, health systems have experienced a various range of similar challenges in achieving such family health objectives [2]. According to the WHO's perspective, Family Physician Program (FPP) is at the center of global efforts to provide personalized, comprehensive, continuous, coordinated and contextualized primary health care for individuals in the context of both family and community $[3,4]$.

In the FPP, family physicians are community-based physicians who take care of patients with nonspecific problems and serve to bridge the gap between health care receivers and the health care system[5], with the hope to incorporate disease prevention and health education within clinical care [4]. The goal of FPP is to establish some advantages for care recipients: 1. Equal enjoyment of health by all persons in the community and implementation of the principle of justice in health; 2 . Removing out-of pocket payments to health system; 3 . Periodic health examination and following up the subjects' health status by the physician, and recording their disease histories; 4. Fast, easy and round-the-clock access to first-level health services, and 5. Improvement of health care delivery system and responding to new people's needs [5].

In 1950, the FPP and Referral Program (RP) were initially launched in the United Kingdom. Afterwards, it was conducted in other countries including Northern Europe, Canada and a series of developing countries, which resulted in improving the efficiency of health systems and social justice [2]. The Islamic Republic of Iran (Iran), as a developing country, has already performed two significant health reforms during three past decades; In the mid-1980s, Primary Health Care (PHC) Network was launched in the rural regions with less than 5,000 population [6], which was significantly improved rural health outcomes [7]. However, the PHC services program has not obtained predominant achievements to meet the needs of population over the decades. Also, three important issues, including development of PHC coverage to urban and suburban areas and the PHC accessibility for care-receivers led to arising some challenges [7]. Therefore, in 2005, the FPP for rural residents was implemented [6]. In 2012, Iranian Ministry of Health and Medical Education (MoHME) also initially implemented Urban Family Physician Program (UFPP) in all provinces within the country [8]. At the first level of care in the UFPP, health care services are delivered to all age groups including infants and children, adolescents, youth, middle aged individuals, older adults, and pregnant and lactating mothers [9]. Some difficulties with the implementation of the UFPP are reported, including the followings: inappropriate referral system, inadequate feedback from family physicians, unrealistic expectations, high workload, and unspecified financial resources [1]. Such challenges bring to the mind the question that how much have the UFPP had positive impacts on the populations' health. 
Previous studies have indicated that high-quality PHC services are associated with better health outcomes and positive health equity [10]. There is evidence that has shown the positive impact of family physician interventions on improving health outcomes [11] and reducing disparities in health. Previous literature about the health impacts of PHC, shows that PHC is significantly correlated with decreases in mortality rates and increases in life expectancy, and is also related to reducing health disparities measured by income level, geographic location and race/ethnicity $[12,13]$. Studies on the Taiwan Family Physician Program have also shown that the program has had a favorable effectiveness in achieving the goals like lessening the outpatient visits to clinics and hospitals, reduction in people's medical and healthcare costs, increasing the level of satisfaction among care receivers and promoting population health, disease prevention, and control benefits [14]. In Iran, previous studies have shown that the FPP has resulted in better access to health care in rural areas [5] and reduced levels of NMR and IMR [6], but the quality of care and the proper implementation of the referral system continue to be challenging [5]. Searching the literature, a scarcity was found in studies that examined the effects of the UFPP, especially in developing countries, and thus further studies seems to be necessary. Therefore, we decided to assess the health impacts of the UFPP in Bonab County, Iran.

In this County, the UFPP was implemented in 2015 with the main strategy of setting up health complexes. In 2018-2019, a health impact assessment study with mixed-method concurrent design was conducted to investigate the impacts of UFPP on the health of urban households within the County, which is still ongoing. In this paper, we report on the results of quantitative section of the study, within which the trend of healthcare indicators across a ten-year period, from 2008 to 2018, were evaluated and the possible impacts of the UFPP intervention on the trend of the indicators in Bonab County were assessed.

\section{Methods}

Interrupted Time Series Analysis (ITSA) is recommended to evaluate population-level interventions based on demographic variables, and not individual indicators. ITSA is a desired method to evaluate health policies, especially for indicators that measure repeatedly in a defined population over a period of time $[15,16]$. For our analyses, we developed ITSA regression models applying the following steps in Stata V.15 (StataCorp, College Station, Texas, USA).

\section{Step 1: study design and its appropriateness}

\section{Population and data}

The data were collected in the urban area of Bonab County - East Azerbaijan, a northeast province in Iran. The County covers an area of approximately $779 \mathrm{~km}^{2}(1.7 \%$ of the province's total area), which is located 120 kilometers from Tabriz and has a population of about 143752, of which 89006 are urban and 54746 are rural. According to the 2016 Census of Population and Housing, the city's urbanization rate is $63.2 \%$ [17]. Prior to the UFPP, two urban-rural health centers were located in the city, including two annexed health centers and 4 non-annexed urban health centers, with 26 specialized personnel (two general physicians, six midwives and 18 female health professionals). 
After the implementation of the UFPP in March 2015 and launching non-governmental and governmental health complexes, some changes were made to the health system of Bonab County. Currently, each nongovernmental complex consists of five urban community health centers and one health post. In total, five family physicians, 34 family health care providers, two mental health experts (psychologists) and two nutritionists work in each non-governmental health complex. The governmental health complex in the County has 2 urban community health centers, within which two family physicians, 12 family health care providers, one mental health expert and one nutritionist work under supervision of the governmental health complex. For the present study, we examined used the data of the last 11 years on the health indicators extracted from the official annual reports of the Bonab County Health Center.

\section{Intervention and comparison}

The UFPP, as a multi-component intervention, was applied for current study. The components of this intervention included the provision of healthcare services, education, primary prevention, active care, screening and in-time diagnosis, first-level outpatient treatment, referral, receiving feedback, and follow-up based on the feedback. The program was launched in February 2015. In this study, the intervention time was from 2015 to 2018. In contrast, the comparison time was related to the time prior to the implementation of the UFPP (ie, 2008-2014).

\section{Outcome}

The indicators were classified into two categories: process and outcome indicators;

\section{Process indicators}

Healthy fertility indicators included the rates of childbearing counseling and Modern Contraceptive Use (MCU). Maternal indices were the rates of prenatal and postpartum care visit, first time care and at least six-time care visit during pregnancy. Child health indicators were the rates of Assessing Ages and Stages Questionnaires (ASQ) and positive ASQ.

Indicators associated to non-communicable and communicable diseases included the rates of cardiovascular disease screenings for 30 years-old individuals and older, people with $20 \%$ of cardiovascular risk and more for a period of 10 years, people with 30 years of age and older diagnosed with diabetes and hypertension and the care they received, and, the incidence of brucellosis and tuberculosis.

Indicators related to middle-aged population care included the rates of care visits for middle aged women and men, and Clinical Breast Examinations (CBE).Older adults care indicators was the rate of elderly care visits.

Mental health indicators included the rates of mental health assessment and screenings for mental disorders assessment. Health education indicators were the rates of self-care program coverage, student health ambassadors, and health promoting schools. 


\section{Outcome indicator}

Outcome indicators included total fertility rate (TFR), crude birth rate (CBR), rate of childbirth by unskilled personnel, the rates of Cesarean section (CS), delivery in high-risk groups, maternal mortality ratio (MMR), stillbirth rate (SBR), neonatal mortality rate (NMR), 1-59 month old mortality rate, infant mortality rate (IMR), low birth weight rate (LBW), the rates of infants fed by formula milk, and overweight and obesity.

As, measurement for some of the process and outcome indicators was conducted since the time of UFPP initiation, ITSA analysis for those indicators (presented in the results section) was not possible.

\section{Step 2: the impact model}

In order to assess the causal associations between the program (as an intervention) and the outcomes of interest, we used ITSA regression models. To do so, we added three variables into the ITSA model: time variable (trend), which represents the time elapsed from the beginning of the study (2008) to the end of study period (2018); dummy variable (program) that shows the time prior and after the intervention; and interaction term representing the joint effect of the time trend of indicators and the implementation of the intervention.

\section{Step 3: descriptive analysis}

Descriptive analyses were illustrated as means and standard deviations (SD) for numeric variables. The descriptive time trend line charts were used to present the process and outcome indicators over the time. The scatter plots were used to show the changes of process and outcome indicators over the study time points (years).

\section{Step 4: regression analysis}

We applied the segmented regression models suggested by Bernal et al [15].

\section{Step 5: Addressing methodological issues}

Since data for outcome and process indicators were reported annually, we were not able to calculate seasonal analysis. There were some limitations in our study, 1) many process indicators were not measured before implementation of the program, so, it was virtually impossible to compare their data before and after the intervention 2) maternal education level had to be considered as a confounder for maternal, infant and child mortality outcome indicators, but we did not have information on this factor. 3) Some indicators may be overlapped together, which may be changed even without intervention.

\section{Results}

The ratio of some process indicators, including the MCU (63.26 to 31.93), incidence of tuberculosis (11.42 to 7.19) and brucellosis (23.04 to 7.15) had a decreasing trend from 2008 to 2018 . However, the CBE (20.77 to 27.98$)$ was found with an increasing trend. Also, prenatal care visits ( 16.67 to 42.28 ) 
postpartum care visits (72.75 to 80.36 ), first time care visits during pregnancy (60.2 to 72.59 ) and sixtime care visits during pregnancy (49.6 to 56.90) had increasing trends from 2011 to 2018. Changes in process and outcome indicators before and after the implementation of UFPP are shown in Table 1.

\section{Insert table 1 here}

A series of outcome indicators including TFR (1.94 to 2.11), 1-59 Month Mortality Rate (5 to 5.32), LBW (4.26 to 6.73), Formula-fed infant rate (2.97 to 3.1), and Delivery rate in high-risk groups (21.13 to 23.65 ) had increasing trends from 2008 to 2018. In contrast, MMR (27.34 to 18.19), CS (59.06 to 51.83) SBR (.77 to .71), NMR (6.49 to 6.09), IMR (9.68 to 8.52) and CBR (19.52 to 17.73) were in decreasing trends from 2008 to 2018 . Figures 1 to 4 show the changes in process and outcome indicators.

\section{Insert Figures 1 to 4 here}

\section{Process indicators}

\section{Maternal care visits indicators}

Changes in maternal indicators are presented in table 2. The rates of prenatal and postpartum care visits had an increasing trend, over the years. There were significant independent associations between time, the intervention and prenatal care visit rate $(b=3.99, p=0.1$ for time and $b=16.29, p=0.02$ for intervention). Although the trend of changes in prenatal care visit rate was relatively incremental before the intervention, and decreasing after the intervention, the difference was not statistically significant $(b=-4.43, p=0.11)$ due to the non-significant interaction of time and intervention. In contrast, postpartum care visit rate had a significant association with interaction term $(b=-22.83, p=0.002)$. The rate of six-time care visits during pregnancy was relatively constant. The independent impact of time and the intervention on six-time care visit rate during pregnancy was not significant, but the interaction term was significant and the trend of changes in the rate was relatively increasing before the intervention and decreasing after the intervention $(b=-10.32, p=0.01)$. First time care visit rate during pregnancy had an increasing trend over the study years. Although the trend of changes in the rate was relatively increasing before the intervention and decreasing after the intervention, the difference was not statistically significant $(b=-5.59, p=0.15)$, due to the non-significant interaction of time and intervention (table2).

The rate of MCU had a decreasing trend over the one decade covered by the study. There was a significant independent associated effect of time and the interaction term with MCU rate. The coefficient for the interaction term was $-5.13(p=0.004)$. In figure 5 , there was a dramatic change in the slop of the MCU trend before and after the UFPP. The rate of CBE had an increasing trend over the study years. The independent impact of time, intervention and interaction time on the rate of CBE was not significant, which shows that the trend of changes before and after intervention was not different. The incidence rates of TB and Brucellosis had decreasing trends over the years. There was a significant independent association between time and Brucellosis $(b=-6.52, p=0.041)$, but, no significant association was found between the interaction term and these two indicators. 


\section{Outcome indicators}

\section{Mortality indicators}

The independent impact of time and the UFPP on MMR was not significant; as a result maternal mortality rate had a decreasing trend over the study period. Nonetheless, there was a significant slope change for MMR ( $b=24.74, p=0.032)$. NMR and IMR were also found with steadily decreasing trends over the study years, and in contrast, 1-59 MR Rate had a steadily increasing trend over the study years. After intervention, the trends of change related to NMR, IMR and 1-59 MR indicators were decreasing. However, the differences was not statistically significant (for NMR, $b=-0.77, p=0.42$, for IMR, $b=-1.05, p=0.24$ and for 1-59 MR, $b=-0.16, p=0.21$ ), due to the lack of significant interaction of time and intervention between the indicators. Over the decade, the SBR had also a decreasing trend. However, the interaction of time and the intervention on SBR, and slope change before and after the intervention was not significant $(b=-0.04$, $\mathrm{p}=0.54)$ (table2).

\section{Delivery indicators}

Delivery indicators, such as Cesarean delivery rate, indicated increasing trend during the study years $(b=5.43, p=0.002)$. There was a significant interaction between time and intervention for $C S(b=-3.43$, $p=0.01$ ), which represents that the increasing trend was slower after the intervention. The rate of delivery by unskilled attendance had a stable trend during the study years $(b=0.022, p=0.041)$. There was also a significant relationship between the independent impact of time program and interaction term on the indicator. Before intervention, there was an increasing trend in the rate by 2015 , but after the intervention a stable trend was found $(b=-0.022, p=0.041)$.

The rate of delivery in the high-risk group had an increasing trend over the years. The independent impact of time and the program on the indicator was not significant, but the interaction term increased sharply after the intervention $(b=1.85, p=0.001)$, (table 2$)$.

Total Fertility Rate was found with an increasing trend over the years. The independent impact of time and the intervention on TFR was not significant, but the interaction term increased sharply after the intervention $(b=0.076, p=0.021)$. CBR presented a stable trend during the study years. The interaction term on CBR was significant, so that the trend of changes before and after intervention was different, and there was a stable trend before intervention and a decreasing trend after the intervention $(b=-0.98, p=0.034)$. The rate of LBW indicated an increasing trend during the study years. The independent impact of time, intervention and interaction time on LBW was not significant; therefore, the trend of changes before and after intervention was not different. The rate of formula-fed infants showed a stable trend during the study years. Although the trend of change in the indicator was relatively decreasing before the intervention and increasing after the intervention, the difference was not statistically significant $(b=0.48$, $p=0.053$ ), which was due to non-significant interaction of time and intervention for the indicator (table 2).

\section{Insert table 2 here}


Figures 5 and 6 represent scatter plots of process and outcome indicators over the study time points. For each indicator, a significant effect shows a statistically significant difference in the average values of the intervention indicator before and after the intervention times (2016). Significance in the 'time' coefficient shows changes in an indicator over the study time, regardless of the intervention time. In the case of significance in the 'time-intervention interaction', a difference is concluded in the slope of changes for an indicator trend before and after the intervention time.

\section{Insert Figures 5 and 6 here}

\section{Discussion}

In the present study, we aimed to evaluate the trend of healthcare indicators across a ten-year period and to assess the possible impacts of the UFPP intervention on the trend of indicators in Bonab County, Iran. Our findings indicated that the UFPP has resulted in changes in some process indicators such as MCU, the rates of postpartum and six-times care visits during pregnancy. However, other process indicators such as the rates of prenatal care, first-time care visit during pregnancy, and brucellosis and tuberculosis incidence rates were found to not be affected by the intervention, and were still in an aggravating trend. Also, some proximal outcomes such as the rates of delivery in high-risk groups, CS, childbirth by unskilled personnel, TFR and distal outcome indicators such as MMR were positively impacted by the UFPP. However, the trend of other outcome indicators associated to stillbirth, NMR, IMR and 1-59 months MR were found to not be positively impacted by the intervention.

After the implantation of UFPP, the rate of MCU had a remarkably decreasing trend and the rate of TFR was increasing, which may be due to implementing the new population growth policy announced by the Iranian Supreme Leader to increase population [18]. As a consequence of implementing this policy in the frame of UFPP in this period, free of charge contraceptives were not available for all women of fertility age, family planning measures were restricted, and the protocol of distributing contraceptives in health centers were improperly implemented, which may be altogether resulted in an increasing trend in the rate of delivery among high-risk groups (age groups younger than 18 and older than 35). Thus, the health of high-risk mothers and their children was endangered due to childbirth outcomes, such as increase in the rate of LBW [19]. These results are consistent with those reported in a previous study conducted in an Iranian rural population [20]. Although the trend of LBW in our study had an increasing trend after intervention, the increase in slope was not significant, due to the non-significant interaction between time and intervention.

Our findings also showed reductions in the rates of postpartum care visits and six-time care visits during pregnancy after the intervention, which was in line with those reported by Jabari et al [16]. As the number of staff (family health care providers) in the health centers increased, as recommended in the UFPP protocol, we expected an increasing trend in the rate of maternal care, but we did not find such a result. This issue is likely due to the simultaneous launching of the Electronic Health Record Plan (EHRP) with the UFPP, which could have resulted in a remarkable difference in the recorded statistics between 
electronic-based and paper-based registrations. Another possible reason to decline in the rate of maternal care may be the low quality of governmental health sector services [21] after implementing the EHRP, as the healthcare providers had to fill in a high number of electronic forms for a referring mother and thus did not pay enough attention to the needs of clients, and mainly referred them to the private sector based on the electronic system. As a consequence, the rate of maternal care was gradually decreased. Similarly, the limitation of inputs and lack of resources and skilled health care providers have been also reported to restrict the sustainable development of a health care system [10]. However, the issue seems to be explored with a qualitative approach in future studies with the hope to find any possible reason for the problems.

According to previous studies, better access to healthcare services can improve quality [21] and decrease maternal mortality rate [22]. Also, reduction in MMR was considered as a significant achievement of the family physician reforms in previous studies [23, 24]. In our study, however, the findings were not consistent. Although the overall MMR was declining during the whole period, the trend was found to be in an increasing manner after intervention. These contradictory results may be pertinent to social determinants of health and poor quality in health services delivery [16, 25]. As Kablinski et al. suggested, such mismatch between access to healthcare and high maternal mortality rate may be possibly due to low quality of services [26]. Therefore, further investigation on this issue, particularly through qualitative studies to explore any possible obstacles, is also recommended.

In the current study, the rate of CS was relatively upward during ten years. However, according to significant interaction between time and intervention, the trend of changes before and after the implementation of UFPP was different; the increasing trend was faster before intervention and slower after intervention, but the trend was still continued to be increasing after intervention. According to literature [16, 27-29], despite the health interventions and even some great economic and demographic changes, the rate of CS was still in an increasing trend [24]. In Iran, similarly, after implementing the special package provided by the Ministry of Health (MOH) in 2013 to reduce unnecessary CS rate, some reduction was happened, but there is still a long way to achieve a desired rate, as noted in previous studies $[30,31]$. Some measures have previously been recommended to reduce the CS rate including better coordinating maternity care, collecting and measuring more data, tying Medicaid payment to quality improvement, enhancing patient-centered decision making through public reporting [28] and health instructions $[32,33]$.

Although in several previous studies [16, 20,34-36], a decrease in the rate of LBW was reported as an important achievement of family physician programs, we found the UFPP with no positive impact on reducing the trend of this indicator in the studied setting. In a previous study, LBW was found to be associated to family income, and the authors suggested that any improvement in reducing the rate of LBW was highly depended on the associated social determinants such as, income status, maternal education and occupation [37]. As Tu et al. reported, family socioeconomic position (SEP) was usually positively associated with birth weight [38]. Alemo et al. similarly studied the LBW prevalence and its associated factors in Ethiopia and reported that the prevalence of LBW significantly associated with the 
mothers' non-employment, residing in a rural area, unintended pregnancy, non-attending antenatal care, mothers with greater than three births, birth interval less than or equal to two years and intimate partner violence during pregnancy [39].

Since a significant increase was happened in the number of physicians and family health care providers after the implementation of UFPP, we expected an improvement in the rates of prenatal mortality indicators such as, SBR, IMR, NMR, and 1-59MMR. But, the UFPP was found with no significant impact on the indicators. Many studies reported the decreasing trend of such indicators after implementing similar family physician programs $[23,24,40,41]$. Naderi et al. studied the effects of rural FP program on child mortality indicators in rural areas of Iran and reported that after the initiation of program, in 2005, the NMR and IMR decreased in comparison to the previous years, but no significant change was observed in U5MR [6]. Chinhoyi et al. also found that FP and medical officers supply were not significantly associated with the incidence of under-5 mortality [42]. Jabari et al. similarly studied the effects of rural FP program on maternal and child mortality indicators in Iranian rural areas, and reported no significant change in the NMR [16]. All these findings suggest that some healthcare indicators, like child mortality rates, are not only depended on the provision of healthcare services but also affected by some context-originated determinants like socio-cultural, behavioral, economic and policy factors. Several previous studies have emphasized the possible role of income, health education and socio-cultural factors [43-46] in promoting healthcare indicators within different societies. According to the literature, medical care is responsible for only a small percentage of preventable mortality and evidence highlights the importance of social and particularly socioeconomic factors in shaping health [47-49]. Therefore, in order to better implement the UFPP, it is recommended to plan for a revisiting program, with a great focus on social determinants of health. To our knowledge, the present study is the first comprehensive analysis of the effects of the UFPP on health indicators. A limitation of our study was that some new health care services, including the diagnosis of non-communicable diseases (e.g. type 2 diabetes and hypertension), and healthy nutrition and mental health services were incorporated into the PHC since the initiation of the UFPP. Although trends in the associated indicators were increasing after the implementation of the plan, we could not profoundly evaluate the trend through ITSA, which was due to time-limit for intervention and lack of indicators prior to the UFPP. Previous studies on FPP in rural populations have particularly investigated the management of diabetes and hypertension and found that healthcare services with experienced healthcare workers and comprehensive guidelines can play an important role in the prevention and management of non-communicable diseases [50]. Therefore, further studies should be conducted with different approaches, either qualitative or a mixed of methods, among urban population to determine the impact of UFPP on such health indicators.

In this study, we applied the ITSA which may be considered as one of the strongest designs to evaluate the impact of UFFP on health indicators. Similar studies have not been conducted in Iran. In Taiwan, ChyiFeng et al. reviewed the 10-year of health care reform on family practice and studied quality care indicators including structure, process and outcome, and reported that after the initiation of program, the members received more preventive care services compared to non-members [51]. While reading the findings of present study, we should keep in mind the undeniable role of economic sanctions against Iran 
on the UFPP implementation and funding, and the healthcare indicators as well. Sanctions, as a social determinant of health, have indirectly affected the Iranian health system [52],and directly affected the increasing trend of child mortality rate [53]. The impacts may be through making difficulties in purchasing health care, promoting people's overall welfare, and reducing accessibility to necessities of a standard life like nutritious foods, healthcare and medicine, especially in the lives of patients, women, and children $[54,55]$. With regards to the potential role of family physician programs in quality, costeffectiveness and competency in health care $[2,4]$, qualitative studies should be conducted to explore deeply the efficiency and impacts of the program and to evaluate the process of the plan and identify the possibly wide range of factors associated with the implementation of the program.

\section{Conclusion}

We concluded that the UFPP has had positive influences on some process, proximal and distal outcome indicators, but its positive impacts on the trends of some of critical indicators, including MMR, NMR and IMR are still questionable. Our findings may shed light on the role of some other factors like social determinants of health in the programs like the UFPP. It seems that without paying attention to such health determinants, healthcare indicators can be improved by a limited extent. Therefore, health policymakers and stakeholders, healthcare providers and health practitioners are recommended to take into account the role of such determinants while either developing or revisiting healthcare delivery systems and/or implementing the associated programs aiming at family and community health promotion.

\section{Abbreviations}

WHO: World Health Organization, PSPP:Pedestrian Safety Promotion Program,

\section{Declarations}

\section{Ethics approval and consent to participate}

Ethical approval for this study was obtained from Research Ethics Committee in Tabriz University of Medical Sciences (Ethic code: IR.TBZMED.REC.1398.417).

\section{Consent for publication}

Not applicable.

\section{Availability of data and materials}

All data used for the analysis are available from the corresponding author upon request.

\section{Competing interests}


The authors declare that they have no competing interests.

\section{Funding}

Vice chancellor for research, Tabriz University of Medical Sciences.

\section{Authors' contributions}

$\mathrm{HN}$ has been the lead author on this study and has participated in all steps and the writing process. $\mathrm{PH}$, $\mathrm{MH}, \mathrm{HA}$, together with $\mathrm{ZI}$ were involved in data preparation and data analysis, and participated in all steps of the writing process. All authors read and approved the final manuscript.

\section{Acknowledgments}

We thank all those who supported us to conduct this research.

\section{References}

1. Dehnavieh R, Kalantari AR, Sirizi MJ. Urban family physician plan in Iran: challenges of implementation in Kerman. Medical journal of the Islamic Republic of Iran. 2015;29:303.

2. Sarvestani RS, et al., Challenges of Family Physician Program in Urban Areas: A Qualitative Research. Archives of Iranian Medicine (AIM), 2017. 20(7).

3. Kuang L, et al. Family practice and the quality of primary care: a study of Chinese patients in Guangdong Province. Family practice. 2015;32(5):557-63.

4. Cubaka VK, et al. A global picture of family medicine: the view from a WONCA Storybooth. BMC Fam Pract. 2019;20(1):129.

5. Khedmati J, et al. Evaluation of Urban and Rural Family Physician Program in Iran: A Systematic Review. Iranian Journal of Public Health. 2019;48(3):400.

6. Naderimagham $S$, et al. Impact of rural family physician program on child mortality rates in Iran: a time-series study. Population health metrics. 2017;15(1):21.

7. Moradi-Lakeh M, Vosoogh-Moghaddam A. Health sector evolution plan in Iran; equity and sustainability concerns. International journal of health policy management. 2015;4(10):637.

8. Doshmangir $L$, et al. Infrastructures Required for the Expansion of Family Physician Program to Urban Settings in Iran. Arch Iran Med. 2017;20(9):589-97.

9. The first-level healthcare package for use in urban areas, rural areas and districts. Available from: http://eazphcp.tbzmed.ac.ir/?PagelD=22.

10. Li H, et al. The development and impact of primary health care in China from 1949 to 2015: a focused review. Int J Health Plan Manag. 2017;32(3):339-50.

11. Swanepoel M, Mash B, Naledi T. Assessment of the impact of family physicians in the district health system of the Western Cape, South Africa. African journal of primary health care family medicine. 
2014;6(1):1-8.

12. Mosquera $P A$, et al. The impact of primary healthcare in reducing inequalities in child health outcomes, Bogotá-Colombia: an ecological analysis. Int J Equity Health. 2012;11(1):66.

13. Macinko J, Starfield B, Erinosho T. The impact of primary healthcare on population health in low-and middle-income countries. J Ambul Care Manag. 2009;32(2):150-71.

14. Liang L-L. Impact of integrated healthcare: Taiwan's Family Doctor Plan. Health policy planning. 2019;34(Supplement_2):ii56-66.

15. Bernal JL, Cummins S, Gasparrini A. Interrupted time series regression for the evaluation of public health interventions: a tutorial. Int J Epidemiol. 2017;46(1):348-55.

16. Beyrami HJ, et al. Impact of rural Family Physician programme on maternal and child health indicators in Iran: an interrupted time series analysis. BMJ open. 2019;9(1):e021761.

17. Nasrin HG, Farhad Z, A Comparative Study of the Cities of East Azarbaijan Province in 2016, 2018, Management and Planning Organization of East Azerbaijan Province.

18. Leader Ti.O.o.t.S. General Population Policies. 2014; Available from: https://www.leader.ir/fa/content/11847.

19. Minjares-Granillo RO, et al. Maternal and perinatal outcomes among adolescents and mature women: a hospital-based study in the north of Mexico. J Pediatr Adolesc Gynecol. 2016;29(3):30411.

20. Alizadeh M, Birami HJ, Moradi S. Analysis of trends in birth outcomes and fertility measures in the rural population of east Azerbaijan province, Iran: 2001-2013. Journal of Nursing Midwifery Sciences. 2015;2(3):10-7.

21. Glass DP, et al. The impact of improving access to primary care. Journal of evaluation in clinical practice. 2017;23(6):1451-8.

22. Blas E, Kurup AS, Equity, social determinants and public health programmes. 2010: World Health Organization.

23. Escuriet R, et al. Assessing the performance of maternity care in Europe: a critical exploration of tools and indicators. BMC Health Services Research. 2015;15(1):491.

24. Victora CG, et al. Maternal and child health in Brazil: progress and challenges. The Lancet. 2011;377(9780):1863-76.

25. Alizadeh M, et al. Journal of Clinical Research Governance J Clin Res Gov. 2014;3:152-7.

26. Koblinsky M, et al. Quality maternity care for every woman, everywhere: a call to action. The Lancet. 2016;388(10057):2307-20.

27. Yazdizadeh B, et al. Cesarean section rate in Iran, multidimensional approaches for behavioral change of providers: a qualitative study. BMC Health Serv Res. 2011;11(1):159.

28. Kozhimannil KB, Law MR, Virnig BA. Cesarean delivery rates vary tenfold among US hospitals; reducing variation may address quality and cost issues. Health Aff. 2013;32(3):527-35. 
29. Shoemaker ES, et al. Results of implementation of a hospital-based strategy to reduce cesarean delivery among low-risk women in Canada. International Journal of Gynecology Obstetrics. 2017;139(2):239-44.

30. Behzadifar M, et al. The effect of the health transformation plan on cesarean section in Iran: a systematic review of the literature. BMC Res Notes. 2019;12(1):37.

31. Hakimi S, et al. Decreasing Unnecessary Cesarean Section Rate in North West Iran: A Story from Achievements and Challenges. Current Women s Health Reviews. 2020;16(1):23-5.

32. Khedr NFH, Eldeen MS. Effect of healthy instructions on reducing pregnant women's fear of normal delivery and preferences for cesarean delivery. American Journal of Nursing Science. 2017;6:176-84.

33. $\mathrm{Yu} Y$, et al. Reducing the rate of cesarean delivery on maternal request through institutional and policy interventions in Wenzhou, China. PLOS ONE. 2017;12(11):e0186304.

34. Kringos DS, et al. The European primary care monitor: structure, process and outcome indicators. BMC Fam Pract. 2010;11(1):81.

35. Saltman R, Bankauskaite V, Vrangbaek K, Primary care in the driver's seat?: Organizational reform in European primary care. Vol. 51. 2005: McGraw-Hill Education (UK).

36. Masic I, et al. Public health aspects of the family medicine concepts in South eastern europe. Materia socio-medica. 2014;26(4):277.

37. Alizadeh $\mathrm{M}$, et al. The relationship between social determinants of health and pregnancy outcomes: a retrospective cohort study in Tabriz. J Clin Res Gov. 2014;3(2):152-7.

38. Tu S, et al. Family socioeconomic position and abnormal birth weight: evidence from a Chinese birth cohort. World Journal of Pediatrics. 2019;15(5):483-91.

39. Alemu A, et al., Low birth weight: prevalence and associated factors among newborns at hospitals in Kambata-Tembaro zone, southern Ethiopia 2018. The Pan African Medical Journal, 2019. 34.

40. Ko HS, et al., Multiple birth rates of Korea and fetal/neonatal/infant mortality in multiple gestation. PloS one, 2018. 13(8).

41. Chang J-Y, et al. Decreasing Trends of Neonatal and Infant Mortality Rates in Korea: Compared with Japan, USA, and OECD Nations. J Korean Med Sci. 2011;26(9):1115-23.

42. Chinhoyi RL, Zunza M, Von Pressentin KB. The impact of family physician supply on district health system performance, clinical processes and clinical outcomes in the Western Cape Province, South Africa (2011-2014). African journal of primary health care family medicine. 2018;10(1):1-10.

43. Mirzaei $M$, et al. Investigation the mortality rate of children (infants) in west area of Isfahan province from 2006 to 2012. International Journal of Epidemiologic Research. 2016;3(4):371-5.

44. Sankar M, et al. State of newborn health in India. J Perinatol. 2016;36(3):S3-8.

45. Chang J-Y, et al. Decreasing trends of neonatal and infant mortality rates in Korea: compared with Japan, USA, and OECD nations. J Korean Med Sci. 2011;26(9):1115-23.

46. Vogel RL, Ackermann RJ. Is Primary Care Physician Supply Correlated with Health Outcomes? Int J Health Serv. 1998;28(1):183-96. 
47. Braveman P, Gottlieb L. The Social Determinants of Health: It's Time to Consider the Causes of the Causes. Public Health Rep. 2014;129(1_suppl2):19-31.

48. Preda A, Voigt K. The social determinants of health: Why should we care? The American Journal of Bioethics. 2015;15(3):25-36.

49. Koffi AK, et al., Sociodemographic, behavioral, and environmental factors of child mortality in Eastern Region of Cameroon: results from a social autopsy study. Journal of global health, 2017. 7(1).

50. Farzadfar F, et al. Effectiveness of diabetes and hypertension management by rural primary healthcare workers (Behvarz workers) in Iran: a nationally representative observational study. The Lancet. 2012;379(9810):47-54.

51. Jan C-F, et al. A 10-year review of health care reform on Family Practice Integrated Care ProjectTaiwan experience. Family practice. 2018;35(4):352-7.

52. Massoumi RL, Koduri S. Adverse effects of political sanctions on the health care system in Iran. Journal of global health, 2015. 5(2).

53. Gutmann J, Neuenkirch M, Neumeier F. Sanctioned to Death? The Impact of Economic Sanctions on Life Expectancy and its Gender Gap. The Journal of Development Studies, 2020: p. 1-24.

54. Kokabisaghi F. Assessment of the effects of economic sanctions on Iranians' right to health by using human rights impact assessment tool: a systematic review. International journal of health policy management. 2018;7(5):374.

55. Gorji A. Sanctions against Iran: The Impact on Health Services. Iranian journal of public health, 2014: p. 381-2.

\section{Tables}

Table 1. Primary health indicators before (2008-2014) and after (2015-2018) the Family Physician program implementation in urban areas of Bonab- East Azerbaijan, Iran 


\begin{tabular}{|c|c|c|c|}
\hline \multirow[t]{2}{*}{$\begin{array}{l}\text { Indicator } \\
\text { category }\end{array}$} & \multirow[t]{2}{*}{ Indicator } & $\begin{array}{l}\text { Before } \\
\text { intervention }\end{array}$ & $\begin{array}{l}\text { After } \\
\text { intervention }\end{array}$ \\
\hline & & $2008-2015$ & $2016-2019$ \\
\hline \multirow{24}{*}{$\begin{array}{l}\text { Process } \\
\text { indicators }\end{array}$} & Childbearing counseling rate (mean $\pm S D$ ) & - & $43.08 \pm 10.18$ \\
\hline & Modern contraceptive use rate (mean $\pm S D$ ) & $63.26 \pm 8.44$ & $31.93 \pm 12.10$ \\
\hline & Prenatal care visit rate (mean $\pm S D)$ & $16.67 \pm 5.94$ & $42.28 \pm 4.74$ \\
\hline & Postpartum care visit rate (mean $\pm S D$ ) & $72.75 \pm 15.22$ & $80.36 \pm 17.66$ \\
\hline & First time care visit during pregnancy rate (mean $\pm S D$ ) & $60.2 \pm 6.61$ & $72.59 \pm 8.04$ \\
\hline & $\begin{array}{l}\text { at least six time care visit during pregnancy rate } \\
\text { (mean } \pm S D)\end{array}$ & $49.6 \pm 8.31$ & $56.90 \pm 11.96$ \\
\hline & $\begin{array}{l}\text { assessing Ages and Stages Questionnaires rate (mean } \\
\pm S D \text { ) }\end{array}$ & $51.54 \pm 0$ & $83.91 \pm 2.37$ \\
\hline & positive ASQ rate(mean $\pm S D)$ & $0.12 \pm 0$ & $1.22 \pm 0.37$ \\
\hline & Incidence of brucellosis (mean \pm SD) & $23.04 \pm 20.88$ & $7.15 \pm 4.65$ \\
\hline & Incidence of tuberculosis (mean $\pm S D$ ) & $11.42 \pm 1.96$ & $7.19 \pm 1.61$ \\
\hline & $\begin{array}{l}\text { Cardiovascular disease Screening for } 30 \text { years-old } \\
\text { individuals and older rate (mean } \pm S D \text { ) }\end{array}$ & - & $30.82 \pm 7.7$ \\
\hline & $\begin{array}{l}\text { people with } 20 \% \text { of cardiovascular risk and more for a } \\
\text { period of } 10 \text { years (mean } \pm S D \text { ) }\end{array}$ & - & $1.47 \pm 1.56$ \\
\hline & $\begin{array}{l}\text { people with } 30 \text { years of age and older diagnosed with } \\
\text { diabetes rate (mean } \pm S D \text { ) }\end{array}$ & - & $1.46 \pm 0.68$ \\
\hline & diabetes physician care visit rate (mean $\pm S D$ ) & - & $1.27 \pm 0$ \\
\hline & diabetes non physician care visit rate (mean $\pm S D$ ) & - & $1.68 \pm 0$ \\
\hline & $\begin{array}{l}\text { people with } 30 \text { years of age and older diagnosed with } \\
\text { diabetes rate (mean } \pm S D \text { ) }\end{array}$ & - & $3.19 \pm 1.4$ \\
\hline & hypertension physician care visit rate (mean $\pm S D$ ) & - & $4.09 \pm 5.5$ \\
\hline & hypertension non physician care visit rate (mean \pm SD) & - & $7.68 \pm 11.31$ \\
\hline & Clinical breast Examinations (mean $\pm S D$ ) & $20.77 \pm 5.47$ & $27.98 \pm 7.58$ \\
\hline & middle aged women's care visits rate (mean \pm SD) & - & $18.45 \pm 12.43$ \\
\hline & middle aged men's care visits rate (mean $\pm S D$ ) & - & $14.3 \pm 11.22$ \\
\hline & elderly care visit rate (mean $\pm S D$ ) & - & $22.33 \pm 14.84$ \\
\hline & mental health assessment rate (mean $\pm S D$ ) & - & $25.91 \pm 2.48$ \\
\hline & screenings for mental disorders assessment & - & $23.65 \pm 2.82$ \\
\hline
\end{tabular}




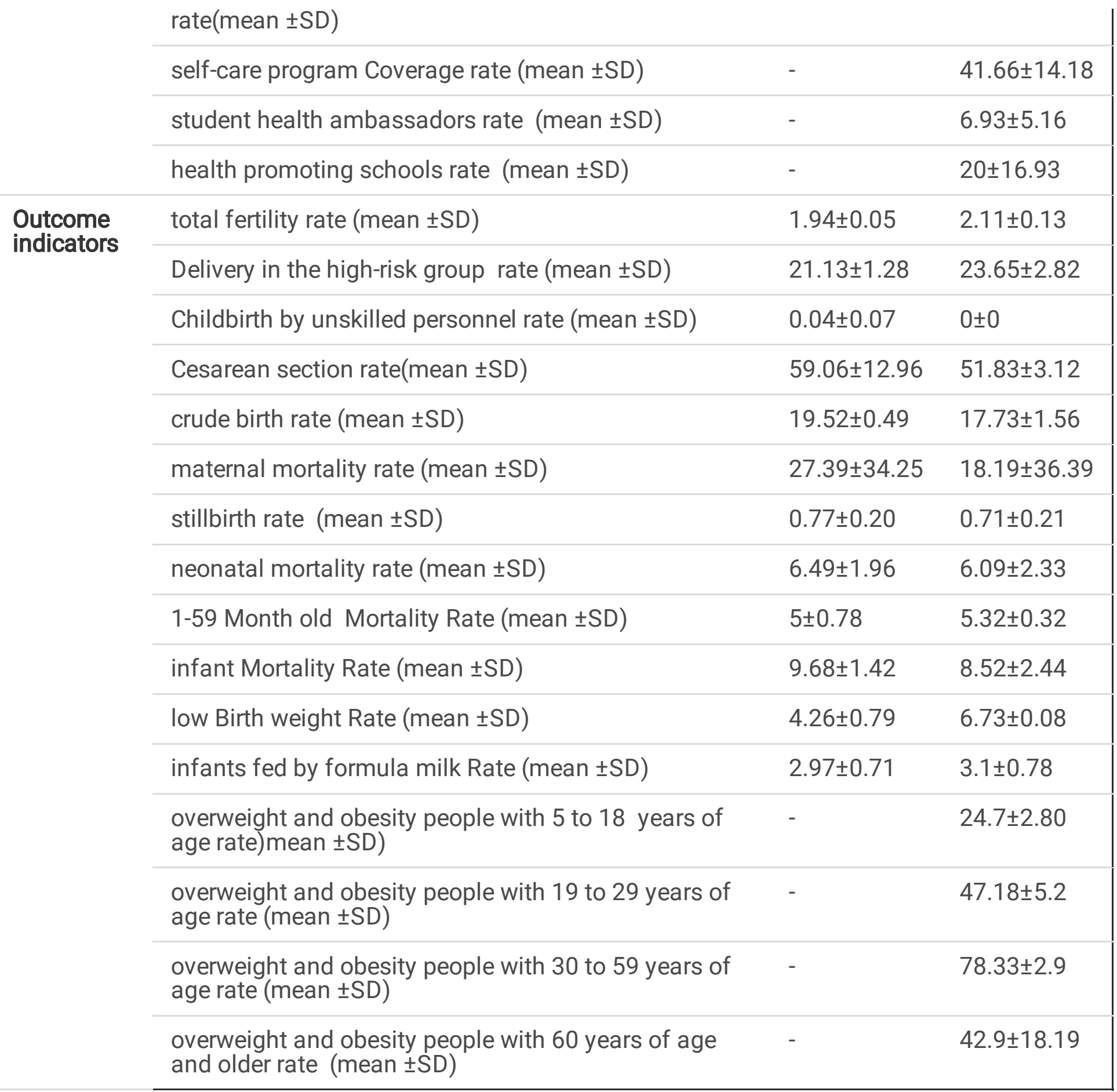


Table 2 Results of ITSA that assess the effect of Family Physician program on health process and outcome indicators in the urban areas of Bonab - East Azerbaijan province, Iran (2008-2018)

\begin{tabular}{|c|c|c|c|}
\hline $\begin{array}{l}\text { Time- } \\
\text { intervention }\end{array}$ & $\begin{array}{l}\text { Intervention } \\
\text { effect }\end{array}$ & \multirow{3}{*}{$\begin{array}{l}\text { Time effect } \\
\text { Coeff ( } L \text { to } U \text { ) }\end{array}$} & \multirow[t]{3}{*}{$\begin{array}{l}\text { Type of } \\
\text { indicator }\end{array}$} \\
\hline interaction & Coeff ( $L$ to $U$ ) & & \\
\hline Coeff ( $L$ to $U$ ) & & & \\
\hline
\end{tabular}

\begin{tabular}{|c|c|c|c|c|}
\hline $\begin{array}{l}-5.13(-8.01 \text { to } \\
-2.26)^{*}\end{array}$ & $\begin{array}{l}-2.70(-12.94 \text { to } \\
7.53)\end{array}$ & $\begin{array}{l}-3.80(-4.7 \text { to } \\
-2.88)^{\star \star}\end{array}$ & $\begin{array}{l}\text { Modern contraceptive use } \\
\text { rate }\end{array}$ & \multirow{2}{*}{$\begin{array}{l}\text { Process } \\
\text { indicators }\end{array}$} \\
\hline $\begin{array}{l}3.04(-3.42 \text { to } \\
9.5)\end{array}$ & $\begin{array}{l}15.45(-6.41 \text { to } \\
37.31)\end{array}$ & $\begin{array}{l}-6.52(-12.68 \\
\text { to }-0.36)^{\star}\end{array}$ & sis & \\
\hline
\end{tabular}

$\begin{array}{lll}0.16(-1.01 \text { to } & -1.55(-5.21 \text { to } & -0.53(-1.27 \text { to } \\ 1.34) & 2.09) & 0.21)\end{array}$

$\begin{array}{lll}-4.42(-10.43 \text { to } & 16.29(3.87 \text { to } & 3.99(1.48 \text { to } \\ 1.58) & 28.70)^{*} & 6.49)^{*}\end{array}$

$\begin{array}{lll}-22.83(-31.44 \text { to } & -2.14(-26.13 \text { to } & 11(5.06 \text { to } \\ -14.21)^{\star} & 21.84) & 16.93)^{\star}\end{array} \quad$ Postpartum care visit rate

$\begin{array}{llll}-5.59(-14.52 \text { to } & 15.59(-7.00 \text { to } & 1.3(-5.98 \text { to } & \begin{array}{l}\text { First time care visit during } \\ \text { pregnancy rate }\end{array} \\ 38.32) & 38.18) & 8.58) & \text { prons }\end{array}$

\begin{tabular}{|c|c|c|c|}
\hline $\begin{array}{l}-10.32(-16.82 \text { to } \\
-3.82)^{\star}\end{array}$ & $\begin{array}{l}14.39(-12.07 \text { to } \\
40.86)\end{array}$ & $\begin{array}{l}2.1(-4.23 \text { to } \\
8.43)\end{array}$ & $\begin{array}{l}\text { Six time care visit during } \\
\text { pregnancy rate }\end{array}$ \\
\hline $\begin{array}{l}0.63(-4.97 \text { to } \\
6.18)\end{array}$ & $\begin{array}{l}5.69(-5.27 \text { to } \\
16.67)\end{array}$ & $\begin{array}{l}0.11(-2.37 \text { to } \\
2.59)\end{array}$ & te \\
\hline
\end{tabular}

\begin{tabular}{|c|c|c|c|c|}
\hline $\begin{array}{l}24.74(2.88 \text { to } \\
46.61)^{\star}\end{array}$ & $\begin{array}{l}-30.29(-91.49 \text { to } \\
30.91)\end{array}$ & $\begin{array}{l}-2.91(-14.96 \\
\text { to } 9.14)\end{array}$ & Maternal mortality rate & \multirow{2}{*}{$\begin{array}{l}\text { Outcome } \\
\text { indicators }\end{array}$} \\
\hline $\begin{array}{l}-0.04(-0.21 \text { to } \\
0.12)\end{array}$ & $\begin{array}{l}0.25(-0.12 \text { to } \\
0.62)\end{array}$ & $\begin{array}{l}-0.04(-0.12 \text { to } \\
0.03)\end{array}$ & Still birth rate & \\
\hline
\end{tabular}

\begin{tabular}{|c|c|c|c|}
\hline $\begin{array}{l}-00.77(-2.91 \text { to } \\
1.36)\end{array}$ & $\begin{array}{l}0.26(-4.19 \text { to } \\
4.7)\end{array}$ & $\begin{array}{l}0.09(-0.57 \text { to } \\
0.76)\end{array}$ & Neonatal mortality rate \\
\hline $\begin{array}{l}-0.16(-0.45 \text { to } \\
0.12)\end{array}$ & $\begin{array}{l}0.33(-1.01 \text { to } \\
1.69)\end{array}$ & $\begin{array}{l}0.04(-0.18 \text { to } \\
0.26)\end{array}$ & 1-59 Month old mortality rate \\
\hline
\end{tabular}

\begin{tabular}{|c|c|c|c|}
\hline $\begin{array}{l}-1.05(-2.99 \text { to } \\
0.89)\end{array}$ & $\begin{array}{l}0.19 \text { (-3.6 to } \\
4.01)\end{array}$ & $\begin{array}{l}0.41(-0.51 \text { to } \\
0.59)\end{array}$ & Infant mortality Rate \\
\hline
\end{tabular}

\begin{tabular}{|c|c|}
\hline $\begin{array}{l}0.33(-0.08 \text { to } \\
0.76)\end{array}$ & $\begin{array}{l}1.29(-0.81 \text { to } \\
3.40)\end{array}$ \\
\hline
\end{tabular}

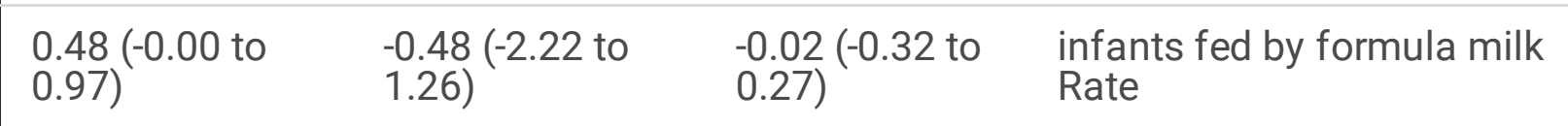

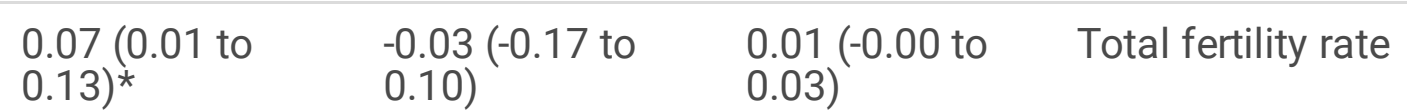




\begin{tabular}{|c|c|c|c|}
\hline $\begin{array}{l}-0.98(-1.86 \text { to } \\
-0.10)^{\star}\end{array}$ & $\begin{array}{l}-0.41(-2.19 \text { to } \\
1.36)\end{array}$ & $\begin{array}{l}0.02(-0.19 \text { to } \\
0.22)\end{array}$ & Crud birth rate \\
\hline $\begin{array}{l}1.85(1.22 \text { to } \\
2.49)^{\star \star}\end{array}$ & $\begin{array}{l}-1.81(-3.71 \text { to } \\
0.09)\end{array}$ & $\begin{array}{l}0.28(-0.07 \text { to } \\
0.64)\end{array}$ & $\begin{array}{l}\text { Delivery in the high-risk group } \\
\text { rate }\end{array}$ \\
\hline $\begin{array}{l}-0.02(-0.04 \text { to } \\
-0.00)^{\star}\end{array}$ & $\begin{array}{l}-1.37(-0.25 \text { to } \\
-0.01)^{\star}\end{array}$ & $\begin{array}{l}0.02(0.00 \text { to } \\
0.04)^{\star}\end{array}$ & $\begin{array}{l}\text { Childbirth by unskilled } \\
\text { personnel rate }\end{array}$ \\
\hline $\begin{array}{l}-3.43(-5.73 \text { to } \\
-1.12)^{*}\end{array}$ & $\begin{array}{l}-31.95(-48.38 \text { to } \\
-15.52)^{\star}\end{array}$ & $\begin{array}{l}5.43(2.77 \text { to } \\
8.08)^{*}\end{array}$ & Cesarean section rate \\
\hline
\end{tabular}

**Significant at 0.01; *significant at 0.05; TB, tuberculosis; ITSA, interrupted time series analysis; L, lower bound of $95 \% \mathrm{Cl} ; \mathrm{U}$, upper bound of $95 \% \mathrm{Cl}$.

\section{Figures}

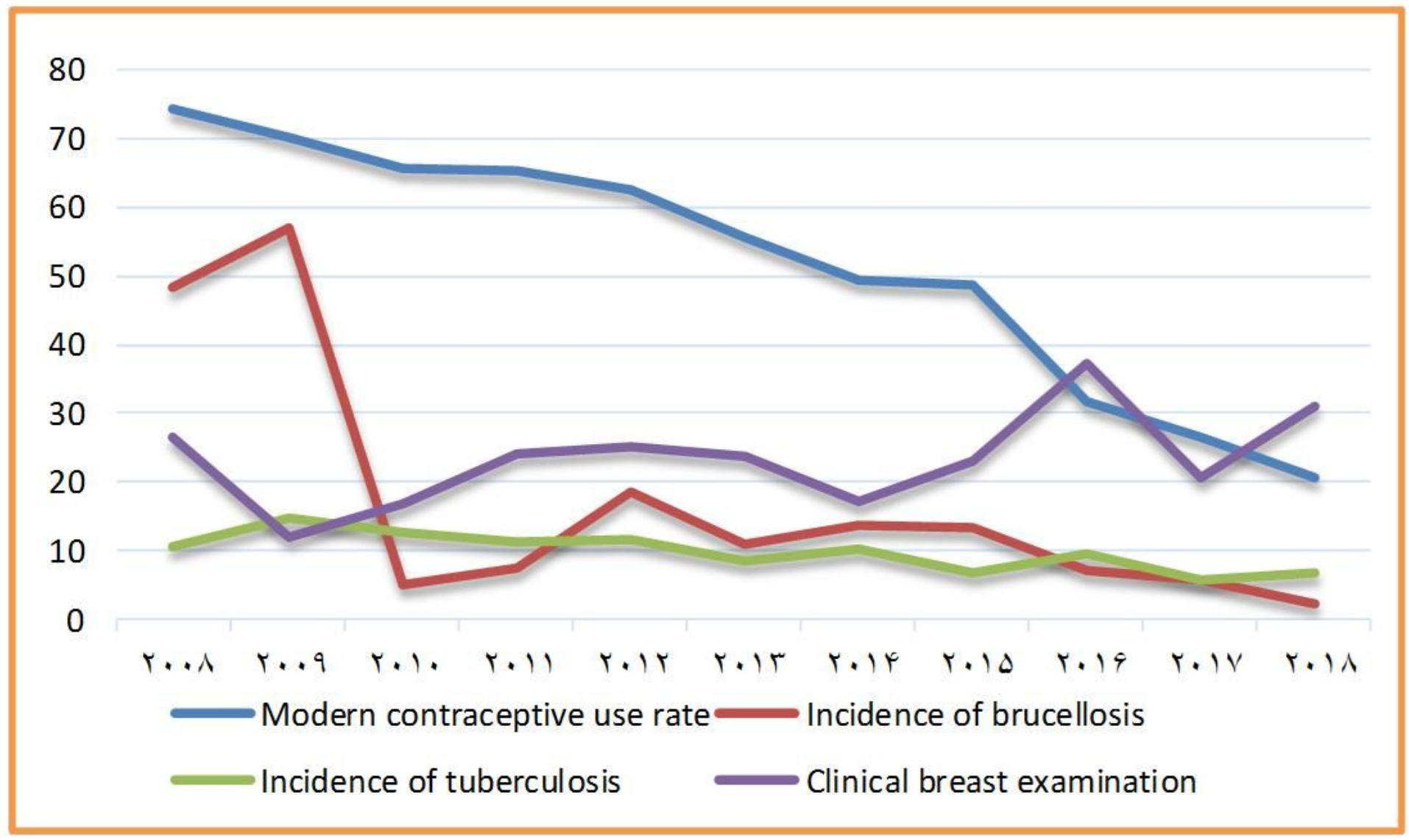

\section{Figure 1}

Trends of changes in process indicators (Modern contraceptive use, Incidence of brucellosis and Tuberculosis and Clinical breast examinations, from 2008 to 2018 in urban areas of County Bonab, East Azerbaijan province, Iran. Source: authors' interpretation of data extracted from the official annual reports of the County Health Center in urban area of the County Bonab, East Azerbaijan, Iran (2008-2018). 


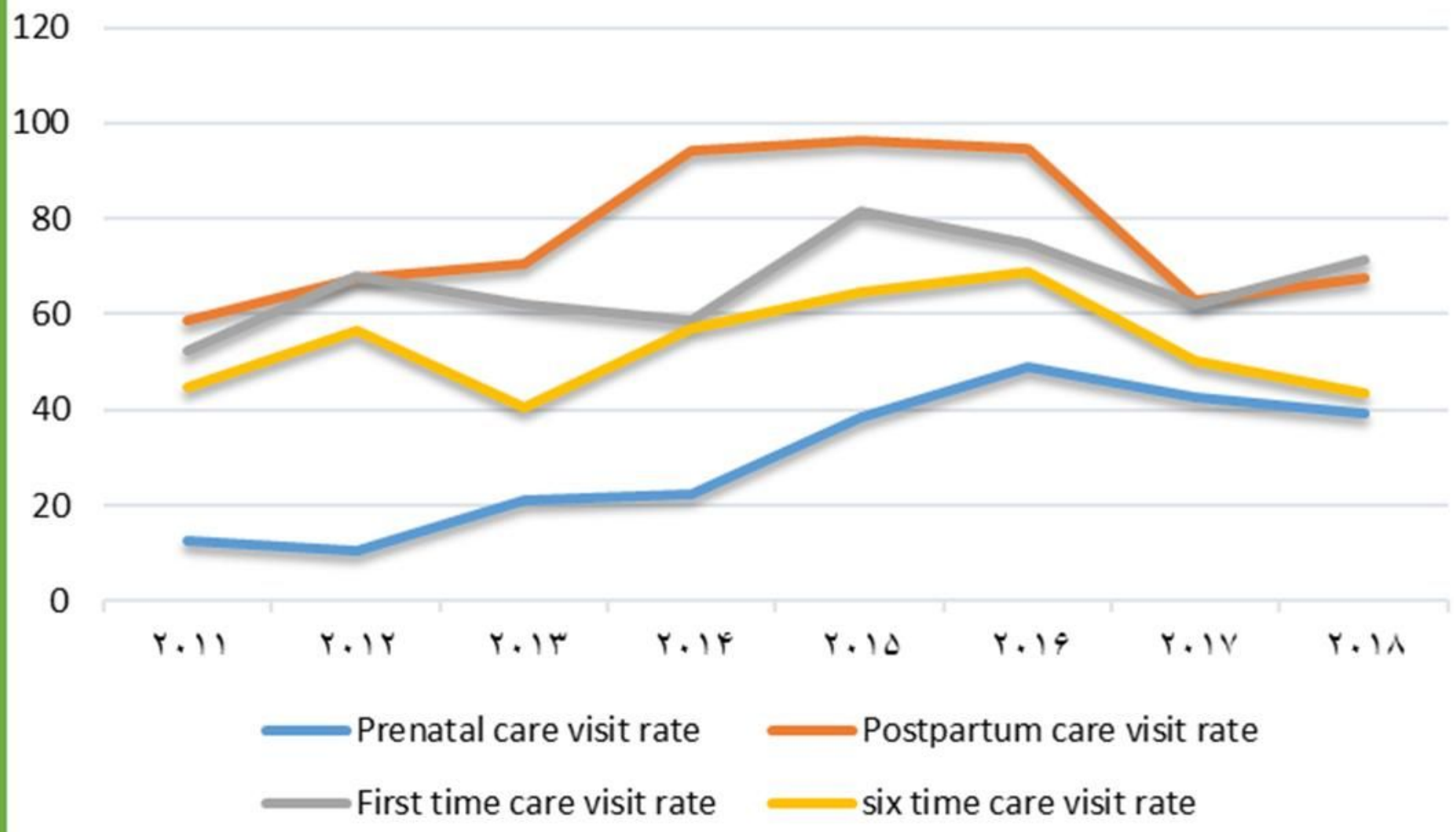

\section{Figure 2}

Trends of changes in process indicators (Prenatal and postpartum care visit, First time and six time care visit during pregnancy rates) from 2011 to 2018 in urban areas of County Bonab, East Azerbaijan province, Iran. Source: authors' interpretation of data extracted from the official annual reports of the County Health Center in urban area of the County Bonab, East Azerbaijan, Iran (2011-2018). 


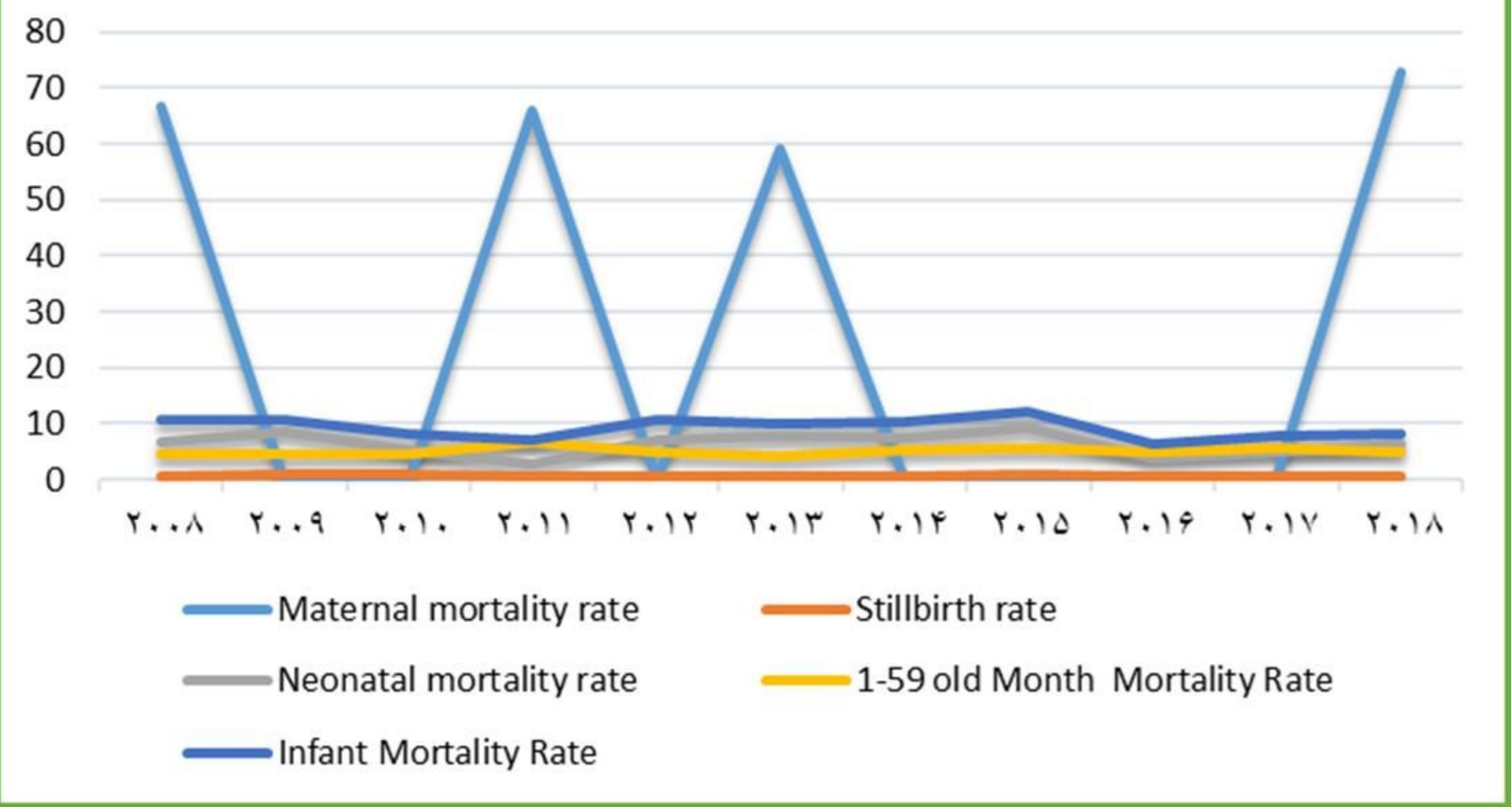

\section{Figure 3}

Trends of changes in neonatal and maternal health outcome indicators (Maternal mortality rate, Stillbirth rate, Neonatal mortality rate, 1-59 Month old Mortality and Infant mortality rate) over the study period (2008-2018) in urban areas of County Bonab, East Azerbaijan province, Iran. Source: authors' interpretation of data extracted from the official annual reports of the County Health Center in urban area of the County Bonab, East Azerbaijan, Iran (2008-2018). 


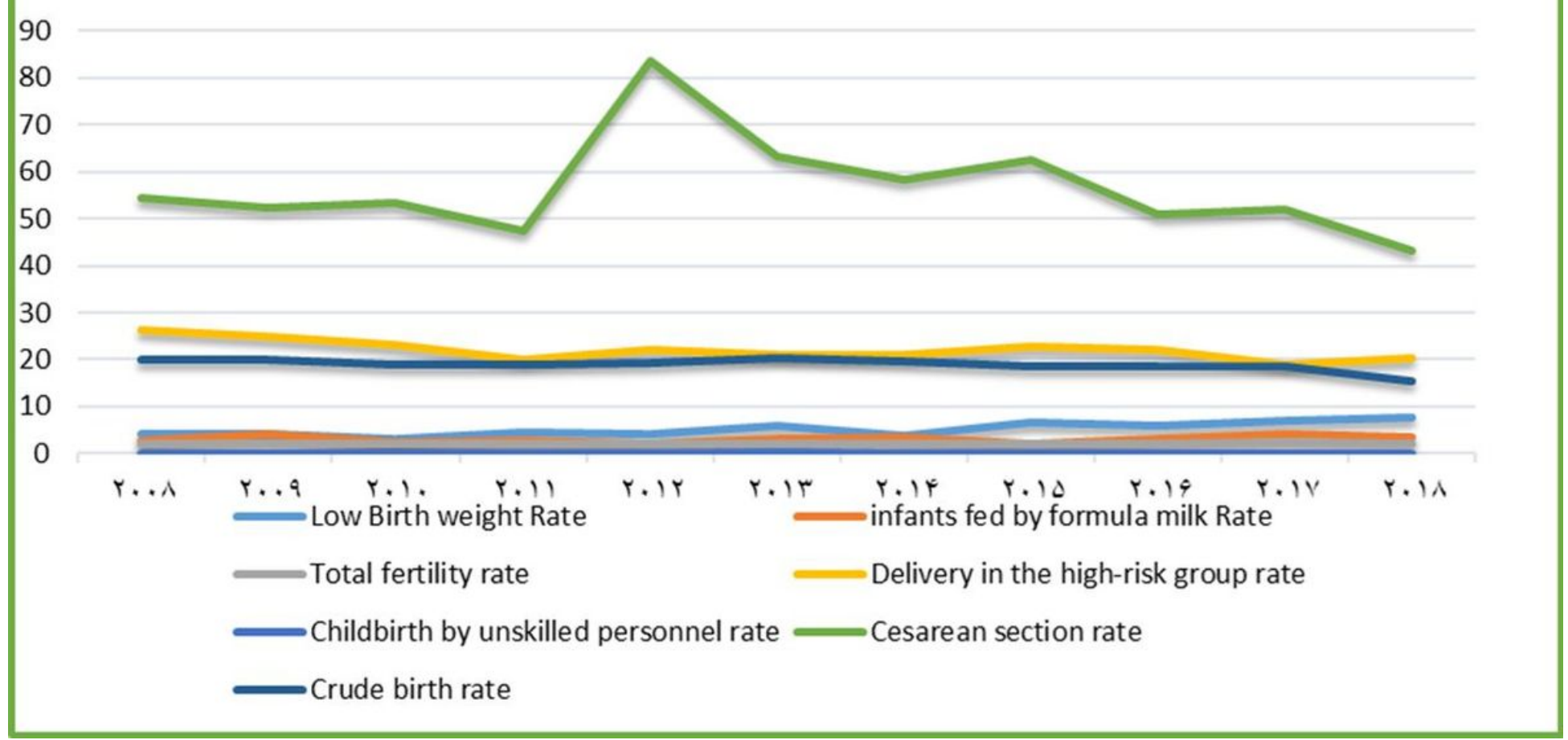

Figure 4

Trends of changes in outcome indicators (Low Birth weight Rate, Total fertility rate, Childbirth by unskilled personnel rate, Crude birth rate, infants fed by formula milk Rate, Delivery in the high risk group rate and cesarean section rate) over the study period (2008-2018) in urban areas of County Bonab, East Azerbaijan province, Iran. Source: authors' interpretation of data extracted from the official annual reports of the County Health Center in urban area of the County Bonab, East Azerbaijan, Iran (2008-2018) 